\title{
LA-UR-20-27053
}

Approved for public release; distribution is unlimited.

Title:

Don't Touch That

Author(s): $\quad$ Bingamon, Brian Michael

Intended for: WESST Promotion

Issued:

2020-09-09 
Disclaimer:

Los Alamos National Laboratory, an affirmative action/equal opportunity employer, is operated by Triad National Security, LLC for the National Nuclear Security Administration of U.S. Department of Energy under contract 89233218CNA000001. By approving this article, the publisher recognizes that the U.S. Government retains nonexclusive, royalty-free license to publish or reproduce the published form of this contribution, or to allow others to do so, for U.S. Government purposes. Los Alamos National Laboratory requests that the publisher identify this article as work performed under the auspices of the U.S. Department of Energy. Los Alamos National Laboratory strongly supports academic freedom and a researcher's right to publish; as an institution, however, the Laboratory does not endorse the viewpoint of a publication or guarantee its technical correctness. 


\section{Don't Touch That}

This video is a fun reminder for glovebox workers to not touch their masks while working in PF-4. 